\title{
The effectiveness of facade systems
}

\author{
Nina Umnyakova ${ }^{1}$, Igor Bessonov ${ }^{1}$, Alex Zhukov², and Ekaterina Zinoveva ${ }^{2, *}$ \\ ${ }^{1}$ NIISF RAASN, Lokomotivny passage, 21, Moscow, Russia \\ ${ }^{2}$ NRU MGSU, Yaroslavl highway, 26, Moscow, Russia
}

\begin{abstract}
The article discusses the results of studying the thermotechnical properties and energy saving factors of insulation systems based on mineral wool products and products based on extruded polystyrene foam under conditions close to natural ones. The studies were carried out on the basis of the hypothesis according to which the heat-saving characteristics of the facade insulation systems are most dependent on the thermal resistance along the surface of the wall, on the thermotechnical uniformity of the insulating sheath and on the stability of the properties of the heatinsulating materials under real operating conditions. The implemented complex made it possible to establish that the smallest difference between the air temperature in the room and the surface temperature in the lower zone was achieved on a fragment of the building envelope with a mounted facade system with XPS as insulation. For the same type of facade system, the maximum heat transfer resistance in the lower zone of the building envelope was reached $-2.72 \mathrm{~m} 2{ }^{\circ} \mathrm{C} / \mathrm{W}$ for the cold period of the year, which significantly exceeds the characteristics of the system of mounted ventilated facades with mineral wool thermal insulation in the corresponding zones. The factor of "additional warming" from the soil, which is used to justify the rejection of warming in the buried part of the structure, does not work in the cold season. Flooding at thezone with the junction of the wall with the soil significantly affects the values and nature of the distribution of operating humidity inside the insulation layers.
\end{abstract}

\section{Introduction}

The heat-saving characteristics of building facades are largely determined by two groups of factors. Firstly, thermal resistance along the smooth surface of the wall. Secondly, the thermotechnical homogeneity of the insulating shell, namely, the reduced thermal resistance, taking into account heat fluxes through windows, doors, and heat-conducting structural elements called cold bridges [1-4].

Thermal resistance depends on the type of thermal insulation material, its operational resistance, and the thickness of the insulating layer. The most widely used insulation systems are products based on mineral (stone) wool and slabs made of extruded polystyrene foam and polyethylene foam. These products are used taking into account their features, which, with incorrect decisions and approaches, turn into disadvantages [5-8]. So mineral wool products have high water absorption and cannot be used in conditions of high

\footnotetext{
* Corresponding author: zinkate@mail.ru
} 
humidity (socle, building perimeter elements in contact with the ground. Extruded polystyrene foam and polyethylene foam are combustible; therefore, products based on it cannot be used in systems of a ventilated space. The elasticity of polyethylene foam does not allow the use of these products in systems of stucco facades with insulation. But makes their use particularly effective in the formation of seamless insulating shells.

The validity of the use of a particular heat-insulating material in the enclosing structures of buildings and structures depends on three groups of factors [9-12]. Firstly, the cost of the material and the cost of its installation during construction work. Secondly, the operational stability of the material and, as a consequence, the durability of the structure and the costs of the current repair of structures and replacement of thermal insulation. Thirdly, the energy efficiency of the adopted constructive solution of the enclosure (insulation shell), which allows to reduce the cost of heating buildings [13-16].

As a rule, specialists working in the construction industry do not take into account the second and third factors, but make a decision based on a comparison of the cost of the insulating material and its installation. However, calculations show that these unaccounted factors make a much larger contribution to the economic efficiency of the material [17-19].

Under the conditions of world and Russian trends to reduce harmful emissions, increase energy efficiency, develop green building and protect the environment, the choice of thermal insulation material for building envelopes should be carried out taking into account all the current groups of factors [20-22].

\section{Experimental}

For a comparative assessment of the operational performance of thermal insulation materials as part of the facade systems, an experimental stand was developed and mounted (Fig. 1), modeling the operating conditions of the main types of thermal insulation materials: mineral wool products, extruded (XPS) expanded polystyrene in a system with bonded thermal insulation and a thin plaster layer (CFTK) and and a hinged facade system with a ventilated layer (MVF system).

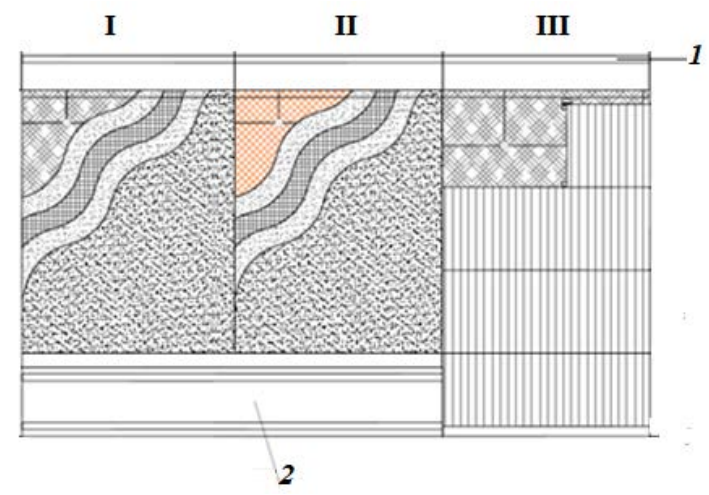

Fig. 1. Schematic diagram of the experimental stand: I - plaster facade (MV-slabs); II - plaster facade (XPS-boards); III - ventilated facade (MV-plates); 1 - galvanized casting; 2 - base formwork

The experimental stand on the device and the materials used fully corresponded to modern facade systems. The thicknesses of the insulation layers were selected based on the standard values of the reduced heat transfer resistance for residential and public buildings in the climatic conditions of Moscow according to SR 50.13330.2012: the thickness of the mineral wool plate (MB-plate) in CFTK and the MVF system is $150 \mathrm{~mm}$, the thickness of the XPS-plate in CFTK is $120 \mathrm{~mm}$ (Fig. 2, 3). 


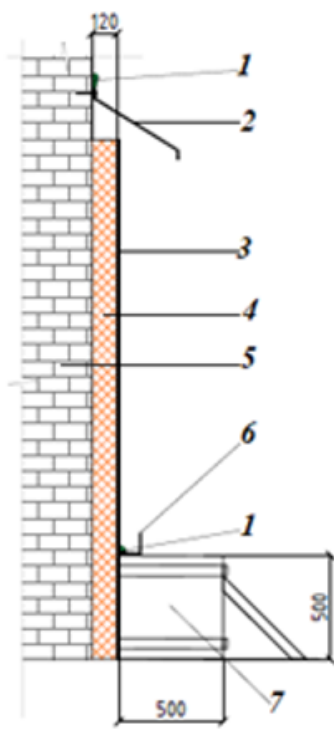

a)

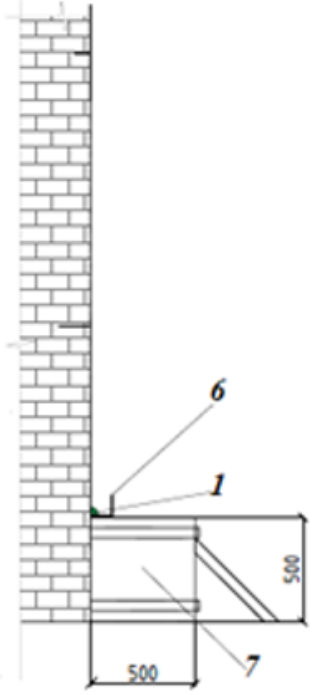

b)

Fig. 2. Facade systems: a - CFTK with insulation from XPS-plates; b - without insulation: 1 - sealant; 2 - galvanized casting; 3 - plaster system; 4 - XPS-plate; 5 - existing brick wall; 6 - L-shaped tray (sealing when adjoining the facade); 7 - formwork construction of the base (filling with soil)

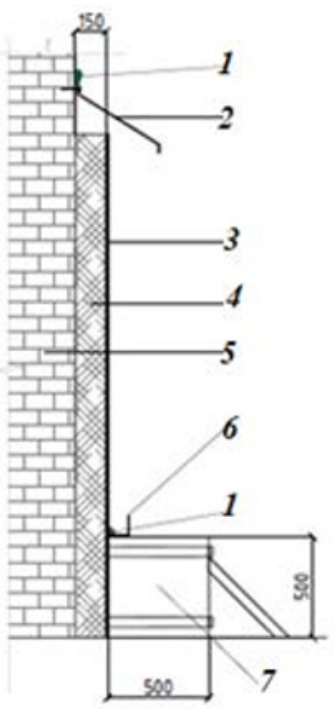

a)

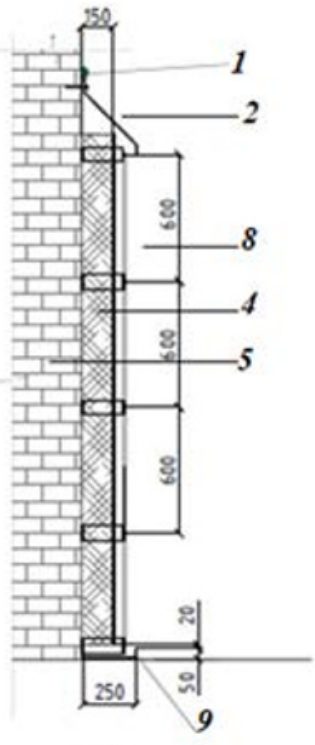

b)

Fig. 3. Facade systems with insulation from mineral wool plates: a - CFTK; $b$ - the system of illegal armed groups; 1 - sealant; 2 - galvanized casting; 3 - thin layer plaster system; 4 - MV-plate; 5 existing brick wall; 6 - L-shaped tray (sealing when adjoining the facade); 7 - formwork construction of the base (filling with soil); 8 - hinged facade system; 9 - tray (galvanized sheet), PVC membrane 
To determine the heat transfer resistance of fragments of the enclosing structure with different types of mounted facade systems, temperature and heat flux sensors of a multichannel meter of heat flux density and temperature were installed on the inner surface of the wall. On each fragment of the building envelope (along the central axis of each system), 2 temperature and heat flux sensors were fixed - in the lower part of the structure (for CFTK buried in the ground) and in the middle part. Sensors in the automatic mode saved indications of temperature on a surface and a heat flux with a periodicity every 10 minutes. Also, in automatic mode, readings of air temperature inside and outside the room were recorded.

\section{Results}

Sampling of insulating materials was carried out in the first half of September and in the late autumn period of the year, the beginning of the heating period (in mid-November). Since mid-September, a water tray modelting flooding at the junction of the wall with soil mounted on a structure filled with soil was filled daily with water. Samples from CFTK were recovered from the soil interface with thermal insulation - the most susceptible to moisture under operating conditions, from the MVF system - from the lower layer of insulation, which in actual use may be soaked also. For sampling, the water trays were pushed back.

Upon removal of all types of heat-insulating materials for research, the insulation layer was conditionally divided into 3 parts (external - in contact with the plaster layer, middle, internal - in contact with brickwork). The results of field experiments to determine the operational humidity of thermal insulation materials in various facade systems after the summer period are presented in table. 1, at the beginning of the heating period - in table. 2 .

Table 1. Exploitation humidity of samples of heat-insulating materials taken from the experimental stand in the first half of September.

\begin{tabular}{|c|c|c|c|}
\hline \multirow{2}{*}{$\begin{array}{c}\text { Type of insulation material / } \\
\text { type of facade system }\end{array}$} & \multicolumn{3}{|c|}{ Exploitation humidity, we, \% } \\
\cline { 2 - 4 } & outer part & middle part & inside part \\
\hline MV-plate / MVF & 0,8 & 1,12 & 0,97 \\
\hline XPS-plate / CFTK & 0,69 & 0,83 & 0,53 \\
\hline
\end{tabular}

Table 2. Exploitation humidity of samples of insulating materials taken in late autumn.

\begin{tabular}{|c|c|c|c|}
\hline \multirow{2}{*}{$\begin{array}{c}\text { Type of insulation material / } \\
\text { type of facade system }\end{array}$} & \multicolumn{3}{|c|}{ Exploitation humidity, we, \% } \\
\cline { 2 - 4 } & outer part & middle part & inside part \\
\hline MV-plate / MVF & 3,04 & 0,73 & 1,53 \\
\hline XPS-plate / CFTK & 1,30 & 1,23 & 1,08 \\
\hline
\end{tabular}

The modeling of flooding at zone of the junction of the wall with the ground, which may occur in reality, for example, as a result of heavy rains before the start of the heating period (Table 2), significantly affected the values and nature of the distribution of operating humidity inside the insulation layers.

The table. 3 shows the measured temperatures on the inner surface of the fragments of the building envelope and the average air temperature indoors, and the table. 4 - calculated 
values of the heat transfer resistance of fragments of building envelopes in the lower and middle zones with different types of facade systems (or without a system) mounted on the outside.

Table 3. Average temperatures on the surface of fragments of the building envelope and internal air.

\begin{tabular}{|c|c|c|c|c|c|}
\hline \multirow[b]{2}{*}{ Zone } & \multicolumn{4}{|c|}{ Internal temperature, ${ }^{\circ} \mathrm{C}$} & \multirow{2}{*}{$\begin{array}{c}\text { Indoor air } \\
\text { temperature, } \\
{ }^{\circ} \mathrm{C} \\
\end{array}$} \\
\hline & $\begin{array}{c}\text { MVF/ } \\
\text { MV-plate }\end{array}$ & $\begin{array}{c}\text { CFTK/ } \\
\text { XPS-plate }\end{array}$ & CFTK / MV-plate & $\begin{array}{c}\text { Brick, masonry } \\
\text { without insulation }\end{array}$ & \\
\hline Lower & 22,2 & 25,0 & 22,8 & 18,3 & \multirow{2}{*}{25,4} \\
\hline Average & 23,4 & 25,2 & 22,9 & 19,4 & \\
\hline
\end{tabular}

Table 4. Average values of heat transfer resistance of fragments of the building envelope.

\begin{tabular}{|c|c|c|c|c|}
\hline Zone & $\begin{array}{c}\text { MVF/ } \\
\text { MV-plate }\end{array}$ & $\begin{array}{c}\text { CFTK/ } \\
\text { XPS-plate }\end{array}$ & CFTK / MV-plate & $\begin{array}{c}\text { Brick, masonry } \\
\text { without insulation }\end{array}$ \\
\hline Lower & 1,12 & 2,74 & 1,86 & 0,82 \\
\hline Average & 1,07 & 2,61 & 1,79 & 0,76 \\
\hline
\end{tabular}

The averaged values of the heat transfer resistance of different fragments enclosing the structures in the lower zone (including for SFTK - in the zones buried in the ground) were: for non-organic powder $-1.21 \mathrm{~m} 2 \cdot{ }^{\circ} \mathrm{C} / \mathrm{W}$; for CFTK (mineral wool boards) $-2.00 \mathrm{~m} 2 \cdot{ }^{\circ} \mathrm{C} /$ $\mathrm{W}$; for SFTK XPS-plate) $-2.72 \mathrm{~m} 2 \cdot{ }^{\circ} \mathrm{C} / \mathrm{W}$; for masonry $-0.76 \mathrm{~m} 2 \cdot{ }^{\circ} \mathrm{C} / \mathrm{W}$.

The fixed so low values of resistance to heat transfer at the MFS are also related to the location of this system on the corner of the building. At the same time, it is of interest to compare the heat transfer resistance of fragments in the lower and middle zones for the building envelope with SFTK - for this system, a soil tank (in the lower zone) was mounted outside, modeling a part of the construction are deepened in the soil. Thermotechnical indicators in the middle and lower zone are close to each other (tab. 3, 4). Also interesting is the fact that in the warmer season (when the outdoor temperature was stable above $0^{\circ} \mathrm{C}$ and the average was $+3^{\circ} \mathrm{C}$ ) - for all SFTK fragments, the heat transfer resistance in the lower zone was higher than in the middle.

\section{Discussion}

As a result of a set of field studies of the operational properties of various types of heatinsulating materials as part of facade systems, the following patterns were established:

- The smallest difference $\left(0.4^{\circ} \mathrm{C}\right)$ between the room temperature and the surface temperature in the lower zone was achieved on a fragment of the building envelope with a mounted facade system with XPS as insulation. For the same type of facade system in the lower zone, the maximum heat transfer resistance in the lower zone of the building envelope was reached $-2.72 \mathrm{~m} 2 \square \mathrm{oC} / \mathrm{W}$ for the cold season, which significantly exceeds the characteristics of the NVF system with mineral wool thermal insulation in the corresponding zones;

- The highest temperatures between the insulation layer and masonry for all the studied areas were recorded in the CFTK version with XPS-plates, while they are much higher than the corresponding temperatures recorded for the MVF system with mineral wool insulation, which indicates the best heat-shielding characteristics of such a facade option systems in operation during the cold season;

- The factor of "additional insulation" from the soil, which is used to justify the rejection of insulation in the buried part of the structure, does not work in the cold season, 
which is most likely due to freezing of the soil and, accordingly, an increase in its thermal conductivity;

- The temperatures for all CFTK variants in the zone buried in the ground are close to the temperatures in other zones, which confirms the need for insulation of this zone in the enclosing structures.

The modeling of flooding in the zone of the junction of the wall with the soil significantly affects the values and nature of the distribution of operating humidity inside the insulation layers. This fact is one of the confirmations of the correctness of entering into the code of rules "Residential and public buildings. Rules for the design of thermal protection" clarification: “ In parts of structures subject to constant exposure to ground, rain or process water, as well as with an increased risk of damage to the protective shells (foundations, ground and basement floors), it is recommended to use heat-insulating materials with minimal indicators of operational humidity, vapor permeability, moisture permeability and capillary absorption, immune to liquid moisture."

\section{Conclusions}

Thermal resistance depends on the type of thermal insulation material, its operational resistance, and the thickness of the insulating layer. Depending on the operating conditions, the most used materials are stone wool and extruded polystyrene foam products. In facade systems with a ventilated space, it is advisable to use mineral wool products because of their incombustibility and satisfactory thermal performance. In systems of stucco facades with insulation, facades with the use of extruded polystyrene foam have the best performance in terms of thermal performance due to their moisture resistance, low water absorption and low heat conductivity with the implementation of scattering and frames of their non-combustible thermal insulation. Extruded polystyrene foam and polyethylene foam are combustible, therefore products based on them can be used only in systems with protection of the heat-insulating layer. The elasticity of polyethylene foam does not allow the use of these products in systems of stucco facades with insulation, but makes their use particularly effective in the formation for seamless insulating shells.

\section{References}

1. B. Rumiantcev, A. Zhukov, D. Zelenshikov, A. Chkunin, K. Ivanov, Yu.Sazonova, Insulation systems of the building construtions, MATEC Web of Conferences, v. 86, (2016). DOI: http://dx.doi.org/10.1051/matecconf/ 20168604027.

2. B. Rumiantcev, A. Zhukov, E. Bobrova, I. Romanova, D. Zelenshikov, T. Smirnova, The systems of insulation and a methodology for assessing the durability, MATEC Web of Conferences, v. 86, (2016). DOI: http://dx.doi.org/10.1051/matecconf/ 20168604036.

3. A. Zhukov, E. Bobrova, D. Zelenshchikov, R. Mustafaev, A. Khimich, Insulation systems and green sustainable construction, Advanced Materials, Structures and Mechanical Engineering, v.1025-1026, pp. 1031-1034, (2014).

4. P. Zhuk, A. Zhukov, Normative legal base of environmental assessment of building materials: prospects for improvement, Ecology and industry of Russia, № 4, pp. 5257, (2018).

5. M-B. Kodzoev, S. Isachenko, S. Kosarev, A. Basova, A. Skvortzov, M. Asamatdinov, A. Zhukov, Modified gypsum binder, MATEC Web of Conferences, v. 170, (2018). DOI: https://doi.org/10.1051/matecconf/201817003022 
6. D. Tuchaev, E. Zarmanyan, E. Petrovskiy, A. Zemlyanko, K. Ivanov, A. Zhukov, Thermal insulation systems for the Arctic, IOP Conf. Series: Materials Science and Engineering, (2018). DOI:10.1088/1757-899X/365/3/032015032041

7. A. Zhukov, V. Semyonov, I. Gnip, S. Vaitkus, The investigation of expanded polystyrene creep behavior, MATEC Web of Conferences, v.117, (2017).

8. V. Gagarin, Macroeconomic aspects of the substantiation of energy saving measures by increasing the thermal protection enclosing structures of buildings, Construction materials, №3, pp. 8-161, (2010).

9. I. Bessonov, A. Starostin, V. Oskina, Dimensionally stable fiber insulation, Vestnik MSUCE, №3, pp. 134-139, (2011).

10. V. Hlevchuk, I. Bezsonov, On current thermal performance of mineral wool, Problems of construction of thermal physics, climate systems, and energy efficiency in buildings, pp. 127-135, (1998).

11. S. Shmelev, Ways of selecting the optimal set of energy-saving measures, Construction materials, №3, pp. 7-9, (2013).

12. Patent for Russian Federation invention no. 2645190 «lock technology of thermal insulation material for seamless welding of connecting locks», registered on February $16^{\text {th }}, 2018$.

13. I. Gnip, V. Kerchulis, S. Vaitkus, Confidence intervals forecasting creep deformation of foam polystyrene, Stroitel'nye materialy, No 12, pp. 40-44, (2012).

14. I. Gnip, V. Keršulis, S.Vaitkus, Analytical description of the creep of expanded polystyrene under compressive loading, Mechanics of Composite materials, No 41(4), pp. 357-364, (2005).

15. I. Gnip, S. Vaitkus, V. Kersulis, S.Vejelis, Long-term prediction of creep strains of mineral wool slabs under constant compressive stress, Mech Time Depend Mater, № 16, pp. 31-46, (2012). DOI:10. 1007/s11043-011-9152.

16. I. Gnip, S. Vaitkus, Analytical description of mineral wool creeping deformation during prolonged compression , Building materials, № 11, pp. 57-62, (2013).

17. N. Johnson, F. Leone, Statistics and Experimental Design in Engineering and the Physical Sciences, Moscow: Mir, 1981, v.2, pp.516, (1981).

18. I. Gimenez, M.-K. Faroog, A. Mahi, A. Kondrotas, M. Assarar, Experimental analysis of mechanical behavior and damage development mechanisms of PVC foams in static tests, Materials Science (Medžiagotyra), No 10 (1), pp. 34-39, (2004).

19. Y. Wang, Z. Huang, L. Heng, Cost-effectiveness assessment of insulated exterior wall of residential buildings in cold climate, International Journal of Project Management, No. 25(2), pp. 143-149, (2007).

20. N. Umnyakova, Insulation condition in suspended ventilated facades under the operating conditions of Moscow, Stroymetall, No. 4 (12), pp. 61-63, (2009).

21. N. Umnyakova, V.Tsygankov, V. Kuzmin, Experimental Thermal Engineering Studies for the Rational Design of Wall Structures with Radiation Insulation, Housing Construction, No. 1-2, pp. 38-42, (2018).

22. R. Fedyuk, A. Mochalov, V. Simonov, Trends in the development of norms for thermal protection of buildings in Russia, Bulletin of the Engineering School of the FEFU, № 2 (11), pp. 39-44, (2012). 